\title{
Análise do trabalho em espaço confinado: descontaminação e manutenção de caminhão tanque
}

Analysis of work in confined space in decontamination and maintenance tank truck

\author{
Sandra Cadore Peixoto', Arthur Gustavo Grutzmacher", Tiago Barboza Baldez Solner'"'
}

\begin{abstract}
RESUMO
Um espaço confinado é definido como um espaço com limites de acesso, ventilação inadequada ou insuficiente, não sendo projetado para ocupação humana contínua, possuindo potenciais riscos à saúde e a vida dos trabalhadores na execução de suas tarefas, rotineiros ou não. Este estudo tem como objetivo analisar o processo de descontaminação e manutenção de um caminhão tanque rodoviário, através da identificação dos possíveis riscos e desenvolvimento de procedimentos de segurança no âmbito do trabalho em espaço confinado. A metodologia usada foi uma revisão sobre a literatura de espaço confinado seguido de um estudo de caso e análise dos serviços realizados no caminhão tanque rodoviário. A pesquisa resultou na identificação de diversos problemas no procedimento atual, principalmente devido à falta de gestão da segurança, permitindo assim sugerir medidas para a eliminação dos riscos. O estudo por fim ressalta a importância da saúde e segurança dos trabalhadores como fator essencial para a preservação da vida e força de trabalho, além de dar subsídios para a empresa atender a legislação vigente.
\end{abstract}

Palavras-chave: Espaço Confinado; Gestão da segurança; Caminhão tanque rodoviário; Saúde e segurança

\section{ABSTRACT}

A confined space is defined as a space with limited access, inadequate or insufficient ventilation, not being designed for continuous human occupation, presenting potential risks to health and life of workers in carrying out their tasks, routine or not. This study aims to analyze the process of decontamination and maintenance of a truck tank, by identifying the possible risks and developing safety procedures within the scope of work in confined space. The methodology employed has supported by literature about confined space followed by a case study and analysis of the services carried out in the truck tank. The resultes in the identification of several problems in the current procedure, mainly due to the lack of security management, thus allowing suggesting measures for the elimination of risks. The study finally underscores the importance of the health and safety of workers as an essential factor for the preservation of life and workforce, besides giving subsidies for the company to meet the current legislation.

Keywords: Confined Space; Security management; Road tank truck; Health and safety

\section{INTRODUÇÃO}

A Norma Regulamentadora no 33 do Ministério do Trabalho e Emprego estabelece: "Espaço Confinado é qualquer área ou ambiente não projetado para ocupação humana contínua, que possua meios limitados de entrada e saida, cuja ventilação existente é insuficiente para remover contaminantes ou onde possa existir a deficiência ou enriquecimento de oxigênio" (BRASIL, 2012). Conforme citado, os riscos em espaços confinados não se limitam apenas aos ambientais ou ergonômicos, sendo necessário, para garantir a segurança do trabalho nessas condiçóes, o monitoramento e avaliação constante das condiçóes atmosféricas dentro desses espaços.

Em função do grau de risco, os acidentes ocorridos em Espaços Confinados são geralmente fatais, em razáo da falta de conhecimentos dos riscos existentes e de medidas para seu controle ou eliminaçáo, de

'Docente no Programa de Pós-graduação em Ensino de Ciências e Matemática, Universidade Franciscana, Santa Maria, RS, Brasil. sandracadore@unifra.br "Engenheiro Químico e Especialista em Segurança do Trabalho pela Universidade Franciscana, Santa Maria, RS, Brasil. arthurgrutzmacher@gmail.com "'Mestrando no Programa de Pós-graduação em Ensino de Ciências e Matemática, Universidade Franciscana, Santa Maria, RS, Brasil. tiagosolner@gmail.com 
modo a proporcionar melhor fluxo de passagem e trabalho seguro (MARTINS, 2014).

Um Plano de Gestão de Segurança e Saúde do Trabalho em Espaços Confinados é uma ferramenta imprescindível nas empresas que possuam em sua planta locais confinados. Planejar as açóes e condiçóes a esse tipo de trabalho é de fundamental importância, devido ao alto risco presente nesses ambientes, os quais requerem medidas de prevençấo e controle voltados a preservação da saúde e segurança dos trabalhadores (MARTINS, 2014).

Dentro deste contexto a proposta deste artigo é propor sugestóes de melhorias no trabalho de descontaminação e manutenção de caminhōes tanque rodoviários, analisando o ambiente de trabalho, além de identificar os possíveis riscos existentes no local, assim como os procedimentos voltados para a segurança do trabalhador, com o intuito de contribuir para a melhoria das condiçóes de trabalho e o cumprimento da legislação vigente.

\section{REVISÃO DA LITERATURA}

\section{I Espaço Confinado no Brasil}

Os espaços confinados são regulamentados pela NR - Norma Regulamentadora no 33, aprovada pelo MTE - Ministério do Trabalho e Emprego, por meio da portaria ${ }^{\circ} 202$, de dezembro de 2006 e atualizada em 31/08/2012 pela portaria no 1409. Além dessa, a Norma Brasileira - NBR no . 16577:2017 Espaço Confinado - Prevenção de Acidentes, Procedimentos e Medidas de Proteção, dispóe sobre os trabalhos em Espaços Confinados.

Espaços Confinados são áreas não projetadas para a ocupação humana contínua, possuindo meios limitados para a entrada e saída do trabalhador. Pode ser definido como um volume fechado por paredes e obstruçôes que apresenta restriçóes para o acesso, movimentação, resgate de pessoas e ventilação natural, como por exemplo: caldeiras, tanques, poços, transportadores, silos, tubulações, torres, colunas de destilação, caixas de passagem, fornos, moinhos, secadores, prensas, dutos de ventilação, entre outros (KLEIN, 2015). São também encontrados nas usinas sucroalcooleiras, fábricas, empresas, construçôes e indústrias de papel e celulose, indústria gráfica, alimentícia, de borracha e couro, indústria naval e de operaçôes marítimas, químicas e petroquímicas, siderúrgicas e metalúrgicas, na prestação de serviços como os de gás, água e esgoto, eletricidade, telefonia, construção civil e ainda nos porões de navios, caminhōes, túneis, valetas e reatores (KLEIN, 2015).

No Brasil, assim como no mundo todo, o acidente de trabalho representa um problema de saúde pública, devido ao potencial de incapacitar o colaborador, temporária ou indefinidamente, assim como ocasionar a morte, especialmente de pessoas em idade produtiva, gerando assim consequências sócias e econômicas. Deve-se assim considerar como primordial a integridade física e psicológica de todos os trabalhadores, em especial nos casos em que se coloca em risco a saúde e a própria vida. Sendo assim, o presente trabalho contribui de forma a esclarecer aos profissionais sobre a importância das medidas de prevenção a serem tomadas na execução de serviços em locais de espaço confinado.

Para a prevençáo de acidentes, doenças ou mortes, os espaços confinados nas empresas, indústrias ou serviços devem apresentar condição ambiental aceitável, livre de quaisquer riscos, e os critérios técnicos de proteção devem permitir a entrada, permanência e saída do trabalho em seu interior com segurança. Assim, é obrigação da empresa e organizaçôes privadas ou públicas, a colaboração e a participação de todos, no que tange à saúde e segurança no trabalho e dessa forma, cada um deve assumir as responsabilidades a ele atribuídas.

\subsection{Fatores Causadores de ACIDENTES EM Espaços Confinados}

Acidentes e óbitos em Espaço Confinado ocorrem devido a um conjunto de vários fatores, tornando-se extremamente necessário a realização de análises preliminares. Pode-se citar alguns exemplos: subavaliação dos riscos, espaço confinado não reconhecido, baixa percepção dos riscos, confiança nos sentidos, despreparo para resgates, bloqueio de equipamentos, falta de Equipamentos de Proteção Individual (EPI) e testes de atmosfera. Esses acidentes, geralmente com resultados graves, podem ocorrer devido à falta de previsão de controles preventivos na execuçáo dos procedimentos internos das empresas.

Nem sempre estes ambientes são facilmente identificados, devido até mesmo a inexistência em determinadas situaçóes, porém, em algumas atividades, o risco pode ser iminente, pois como não se pode esquecer pela definição do mesmo, o risco pode se desenvolver conforme a atividade executada. Dessa forma, todas as 
informaçóes quanto aos locais, perigos e riscos devem ser repassadas aos trabalhadores, de forma a prevenir que os mesmos sejam acessados por trabalhadores despreparados.

\subsection{Controle para entrada em Espaço Confinado}

Para um bom controle operacional deve-se dar prioridade a eliminaçóes dos perigos ou evitar a existência dos mesmos, prevenindo assim a ocorrência de acidentes. Realizar essa forma de controle implica em utilizar novas tecnologias, mudança de processos e investimentos na busca de melhores resultados.

Deste modo empresa deve aplicar ou desenvolver processos de prevenção eficientes, estabelecendo os controles necessários, levando em consideração diversos fatores, tais como: a fonte do perigo, o meio, o indivíduo, o nível de risco, a praticidade do controle e a possibilidade de náo gerar novos perigos. Para tanto, antes de entrar em um Espaço Confinado, deve-se seguir o seguinte fluxograma e focar na atividade a ser desenvolvida no local (figura 1).

Figura 1 - Procedimento para trabalho em Espaço Confinado

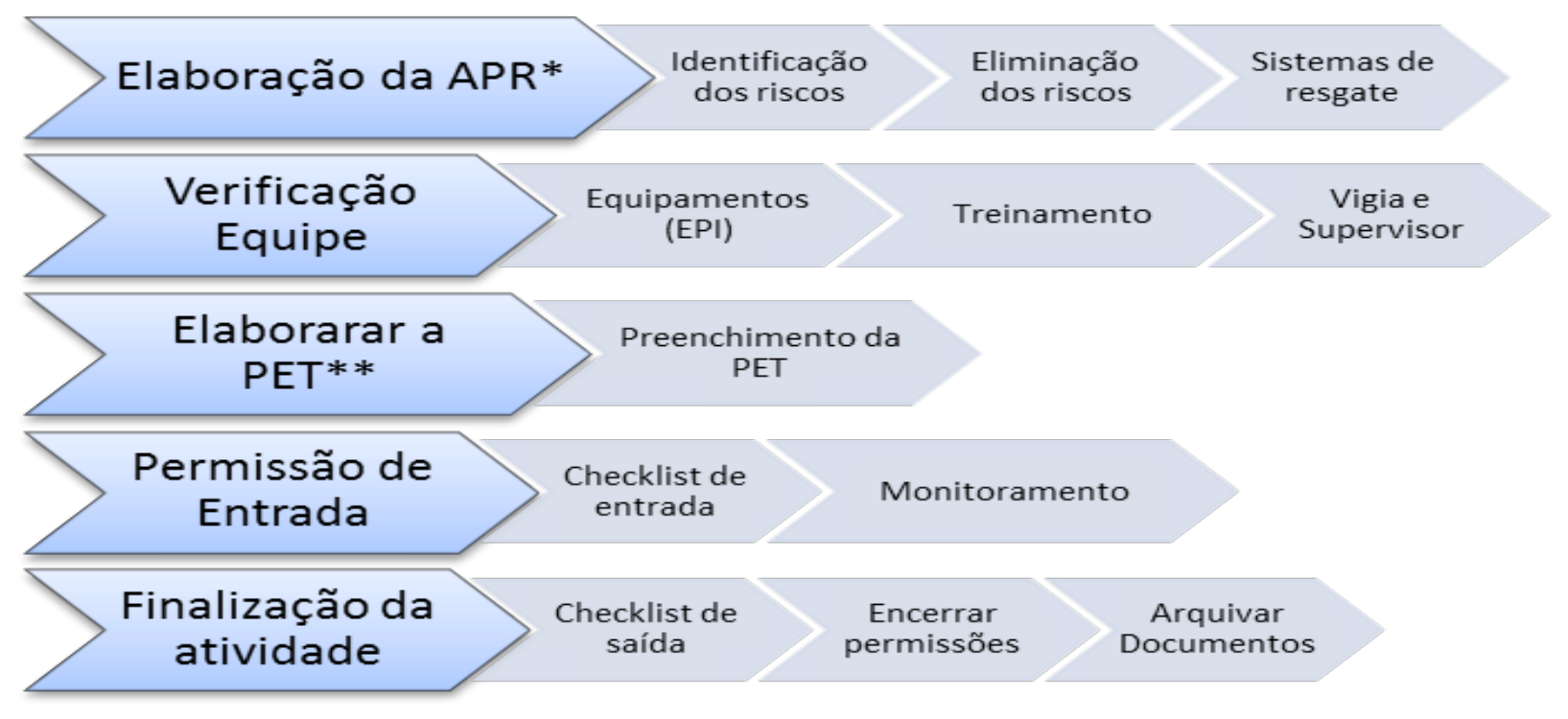

* APR: Análise preliminar de risco.

** PET: Permissão de Entrada de Trabalho.

Fonte: Próprio autor.

Tabela 1 - Procedimentos para emissão da PET

\begin{tabular}{|c|c|}
\hline Guardar o Espaço & Posicionar sinais de advertência ou barreiras de forma a manter afastado pessoas não autorizadas. \\
\hline Isolamento do espaço & $\begin{array}{l}\text { Desconectar, trancar ou sinalizar equipamentos que podem ser perigosos ao trabalhador dentro do } \\
\text { espaço confinado. }\end{array}$ \\
\hline Teste atmosférico & Testar os perigos atmosféricos: oxigênio, gases inflamáveis, tóxicos ou corrosivos. \\
\hline $\begin{array}{l}\text { Eliminaçấo ou controle } \\
\text { atmosférico }\end{array}$ & Eliminação ou controle dos riscos atmosféricos no local, através de métodos de ventilaçáo. \\
\hline Verificação de equipamentos & $\begin{array}{l}\text { Garantir aos trabalhadores equipamentos necessários e em boas condiçóes de uso, com treinamento } \\
\text { para seu uso. }\end{array}$ \\
\hline Planejar emergências & Informar os procedimentos de resgate e emergência \\
\hline Formalizar a permissão de entrada & Após verificação pelo supervisor, assinar a permissão de entrada. \\
\hline Monitoramento das atividades & $\begin{array}{l}\text { Manter comunicação contínua entre os envolvidos assim como monitoramento dos riscos de forma a } \\
\text { manter condiçôes do trabalho. }\end{array}$ \\
\hline
\end{tabular}

Fonte: Próprio autor 
A figura 1 demonstra um fluxograma simples e prático de controle de trabalho em espaços confinados, contendo os procedimentos a serem tomados em cada etapa, de forma que seja garantida primeiramente a segurança e saúde dos trabalhadores, assim como seguir a legislação, principalmente a NR 33.

$\mathrm{Na}$ tabela 1 estão descritos os procedimentos normais a serem adotados antes e durante o acesso a esses espaços, sendo um conjunto simples de ações a serem utilizados na emissão da Permissão de Entrada de Trabalho (PET).

\subsection{Principais Riscos nos Espaços Confinados}

Soterramento, deficiência de oxigênio, riscos ergonômicos, riscos químicos, riscos de explosóes, incêndio, choques elétricos e quedas, estáo entre os principais riscos que se encontram nos espaços confinados. Além desses, são podem ser considerados riscos gerais nestes locais: defeitos nos equipamentos, quedas de objetos no interior do espaço durante a execução das atividades, falta de iluminação, ambiente agressivo com elevado ruído ou vibrações, temperaturas (frias ou quentes), presença de animais e riscos decorrentes da comunicação da parte interna e externa (KLEIN, 2015).

\subsection{RISCOS ESPECÍFICOS}

Há muito tempo já foi estabelecido que é de fundamental importância a verificação dos riscos a que dizem respeito as condiçôes atmosféricas em espaços confinados. Os riscos específicos ocorrem devido ao enriquecimento ou deficiência de oxigênio, incêndio, explosão e a presença de substâncias tóxicas ou químicas. Tais fatores criam uma Atmosfera Imediatamente Perigosa a Vida e Saúde (IPVS), sendo toda condiçáo de atmosfera que ofereça risco imediato à vida ou traga imediato efeito debilitante à saúde, sendo gases e vapores os componentes da maioria dos contaminantes em Espaços Confinados (NAVARRO, 2012).

\subsection{DEFICIÊNCIA DE OXIGÊNIO}

A insuficiência de oxigênio é a maior causa de mortes em espaços confinados, pois não pode ser detectada visualmente e normalmente a vítima não possui tempo ou capacidade de reagir. No Brasil, conforme a NR 33, é considerado deficiência de oxigênio a atmosfera com valor abaixo de $20,9 \%$ em volume, entretanto é aceito o intervalo de 19,5\% até 23,5\% nos ambientes de trabalho (BRASIL, 2012; NAVARRO, 2012).

A Tabela 2 demonstra os efeitos causados pela deficiência de oxigênio.

Tabela 2 - Efeitos causados pela deficiência de oxigênio na atmosfera

\begin{tabular}{c|c}
\hline Efeito do oxigênio por concentração na atmosfera (em volume) & Porcentagem \\
\hline Risco de explosão & Acima de $23 \%$ \\
\hline Faixa normal de trabalho & 19,5 até $23 \%$ \\
\hline Descoordenação & 15 a $19 \%$ \\
\hline Respiração acelerada & 12 a $15 \%$ \\
\hline Náusea & 10 a $12 \%$ \\
\hline Inconsciência & 8 a $10 \%$ \\
\hline Morte após 8 minutos & 6 a $8 \%$ \\
\hline Coma em 40 segundos seguido de morte & 4 a $6 \%$ \\
\hline
\end{tabular}

Fonte: Navarro (2012)

\subsection{PRESENÇA DE SUBSTÂNCIAS TÓXICAS}

Em um espaço confinado pode-se encontrar uma infinidade de substâncias químicas tóxicas ao ser humano, onde a existência desses contaminantes podem causar consequências de uso ou nas condiçóes ambientais, tais como: oxidação, vazamentos, fermentação, decomposição de matéria orgânica e erros operacionais. Para detecção e avaliação sobre a presença de substâncias químicas são usados principalmente dois parâmetros para a permissão de trabalho em espaços confinados: atmosfera Imediamente Perigosa à Vida e Saúde (IPVS) e Limite de Tolerância (LT) (NAVARRO, 2012).

Dado que as substâncias químicas possuem características singulares, e que nenhum produto deve ser manuseado sem que se conheçam os riscos associados a ela, deve-se sempre consultar a Ficha de Informaçóes de Segurança de Produtos Químicos (FISPQ) (CORDEIRO, 2013). Na tabela 3 têm-se exemplos de substâncias e os limites de tolerância pela legislação brasileira estabelecido pela NR 15 (BRASIL, 2014). 
Tabela 3 - Limite de tolerância de substâncias químicas

\begin{tabular}{cc}
\hline \multicolumn{2}{c}{ Limite de tolerância de substâncias químicas } \\
\hline Amônia & $20 \mathrm{ppm}$ \\
\hline Cloro & $0,08 \mathrm{ppm}$ \\
\hline Dióxido de carbono & $3900 \mathrm{ppm}$ \\
\hline Dióxido de enxofre & $4 \mathrm{ppm}$ \\
\hline Gás sulfídrico & $8 \mathrm{ppm}$ \\
\hline
\end{tabular}

Fonte: NR 15 (BRASIL, 2014)

\subsection{ATMOSFERAS INFLAMÁVEIS}

São a partir dos níveis de oxigênio, poeiras, vapores e gases presentes na composição atmosférica que tornam o ambiente inflamável ou explosivo, pois toda substância química tem limites de explosão que, ao serem acrescentados a uma atmosfera rica em oxigênio podem causar uma combustão (MARTINS, 2014). De fato, sabe-se que são necessários três elementos para que haja fogo: oxigênio, calor e combustível. Assim, as substâncias químicas no ambiente confinado agem como o combustível e, por isso, deve-se atentar as características exclusivas de cada uma como ponto de fulgor, limites inferior e superior de explosividade, densidade do vapor e temperatura de ignição (NAVARRO, 2012).

Através desses conhecimentos é possível tomar as corretas medidas de prevençáo, sendo muitas vezes possível eliminar por completo esse tipo de risco, principalmente ao se eliminar um dos três elementos básicos para a presença de fogo.

\subsection{GESTÃo de SEGURANÇA EM ESPAÇO CONFINADO}

Faz parte da empresa adotar um programa de Gestáo da Segurança no Trabalho em Espaços Confinados para garantir que sejam cumpridos adequados procedimentos relativos ao que se determina na NR 33, determinados pelo conjunto de ações preventivas, administrativas, coletivas e pessoal, as quais são essenciais para as atividades realizadas nesses ambientes. A tabela 4 apresenta uma série de procedimentos para essa gestão.

Tabela 4 - Gestão de segurança em Espaços Confinados

\begin{tabular}{cc}
\hline Etapa & Processos \\
\hline Detecção de gases \\
Ventilação \\
Isolamento da área \\
Equipamentos \\
Comunicação \\
Emergência e resgate \\
\hline Administrativo & Procedimento Padrão de Espaço Confinado \\
& Análise preliminar de risco \\
Cadastro de Espaço Confinado & Treinamentos \\
Autorização de Trabalhos (PET) \\
\hline Pessoal \\
Atestado de saúde ocupacional (ASO) \\
Exames médicos periódicos
\end{tabular}

Fonte: Próprio autor.

Os requisitos para execução do programa de gestão da segurança, conforme a ABNT 16577:2017 são: a prática de procedimentos de Permissão de Entrada, documentado e arquivado, adoção de ações para impedir a entrada de pessoas não autorizadas, realização de treinamentos, exames médicos, identificação, análise de risco, serviços de emergência e resgate, equipamentos específicos e em condição de uso, além de aplicação de práticas e procedimento essenciais para a operação segura em espaços confinados (ABNT, 2017). 


\section{I0 RESPONSABILIDADES}

Conforme a NR 33 existem responsabilidades a serem cumpridas pelo empregador e empregados, sendo (BRASIL, 2012):

Responsabilidades do Empregador: Designar responsável técnico pela NR 33, identificar os espaços confinados, seus riscos e métodos de prevenção. Além disso, deve manter a equipe capacitada, documentos administrativos (PET, APR) e implantação da prática de gestão em segurança do trabalho.

Responsabilidades do Empregado: Cumprir os procedimentos e treinamentos recebidos, colaborar com o cumprimento da NR 33, e comunicar qualquer situação de risco.

A NR 33 também define as responsabilidades referentes aos cargos específicos, Vigia e Supervisor de Entrada, que são responsáveis durante a execução das atividades em espaços confinados:

Responsabilidades do Vigia: Permanecer à entrada do espaço confinado monitorando os trabalhadores autorizados, contagem do número de trabalhadores, possuir conhecimento dos riscos e medidas de prevenção, manter comunicação com a equipe, não se envolver com outras atividades, distraçóes ou se ausentar, e por último determinar situaçôes de abandono do espaço confinado ou iniciar os procedimentos de emergência e resgate.

Responsabilidades do Supervisor de Entrada: Conhecer os riscos do trabalho, providenciar a emissão da Permissão de Trabalho, conferir os testes e procedimentos executados, autorizar ou cancelar a permissão de entrada, encerrar a PET após a finalização do trabalho e garantir a disponibilidade de serviços de emergência e resgate.

\section{METODOLOGIA}

Este trabalho tem como caráter um estudo exploratório com o intuito de estruturar um plano de gestão da segurança, além de solucionar problemas na atividade em questão. De forma a viabilizar a análise do procedimento de descontaminaçáo de caminhão tanque, foi realizado um acompanhamento durante a execuçáo dessa atividade no dia doze de dezembro do ano de dois mil e dezessete, em uma empresa do município de Santa Maria (RS), tendo sido observados os procedimentos de execução e administrativos, além dos riscos existentes e equipamentos utilizados.

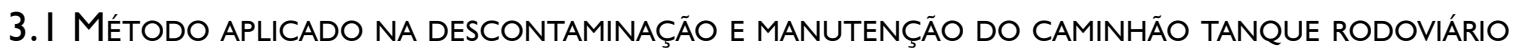

O processo de descontaminação e manutenção de caminhôes tanque em estudo é efetivado por uma empresa do município de Santa Maria (RS), sendo que são realizadas diversas etapas, tais como ventilação, limpeza, purga, e pôr fim à manutenção. Nesta última etapa ocorre a entrada de trabalhadores no espaço confinado (caminhão tanque).

Inicialmente, e de forma que haja condiçóes de trabalho, é necessário reduzir os níveis de gases e vapores presentes dentro do Espaço Confinado, pois a principal carga destes tanques são combustíveis, então é feita a abertura da tampa e inserção de ventilação forçada por exaustão, de forma a eliminar todos os contaminantes tóxicos presentes.

A figura 2 ilustra imagem da etapa de exaustão de um tanque (2a) e de um sistema de exaustão (2b) utilizado no processo.

Após a execução da ventilação, inicia-se o processo de purga, limpeza interna e descontaminação dos tanques, onde são inseridas mangueiras as quais injetam uma mistura de água e um produto químico específico para remoçâo de óleos e sujeiras. A água acaba por ser escoada pelas válvulas de descarga de cada um dos tanques, sendo a mesma encaminhada para a estaçáo de tratamento. Todo esse procedimento envolve em média duas horas, e acaba por eliminar quaisquer gases, vapores e contaminantes no interior do tanque, sendo todos os dados da operação anotados em um documento chamado certificado de descontaminação. Após, um trabalhador adentra os tanques para verificação da integridade dos mesmos, e realiza as atividades de manutenção necessárias, como troca de peças e soldagem. Tal atividade náo possui tempo padrão de execução, podendo variar conforme a quantidade de reparos a serem feitos. Para finalização dos serviços, são feitas uma última verificação e testes de vazamento quando necessários, sendo a liberaçáo do caminháo tanque realizada após o preenchimento do certificado de descontaminação, onde uma cópia é guardada junta a empresa prestadora do serviço. 
Figura 2a - Exaustão de um tanque

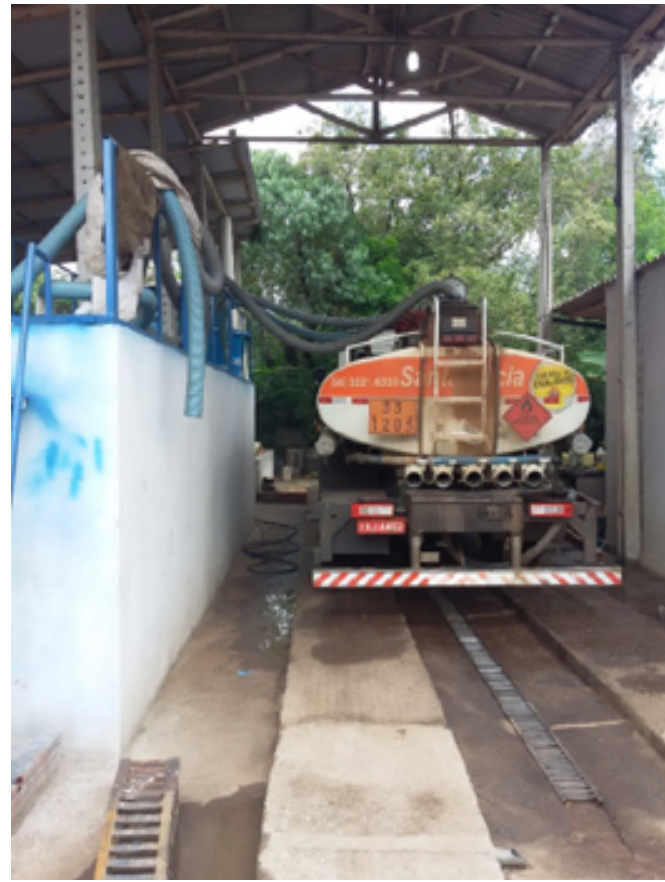

Fonte: Fotos tiradas pelo autor
Figura $2 \mathrm{~b}-$ Sistema de exaustão

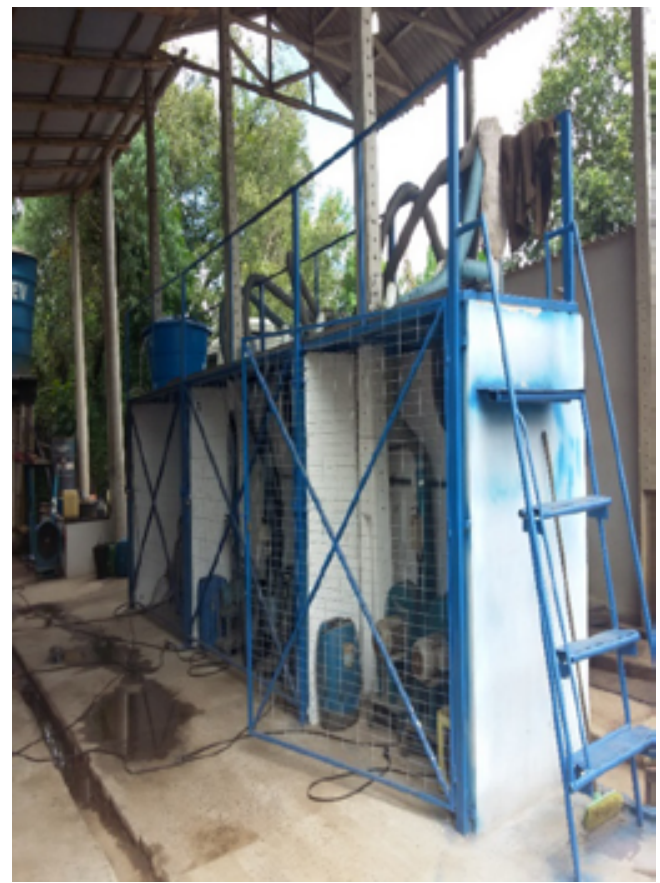

\section{RESULTADOS E DISCUSSÃO}

\section{I IDENTIFICAÇÃO DE RISCOS AO EsPaÇo CONFINADO NA ATIVIDADE DA EMPRESA}

$\mathrm{Na}$ empresa em estudo, o Espaço Confinado foi identificado na execução da atividade de descontaminação e manutenção do caminhão tanque, sendo que o mesmo apresenta diversos riscos ao trabalhador. Dessa forma foi realizado um levantamento dos riscos identificados, conforme tabela 5.

Tabela 5 - Identificação de riscos da atividade no Espaço Confinado

\begin{tabular}{|c|c|c|}
\hline Riscos & Descrição & Consequências \\
\hline Dificuldade de acesso & $\begin{array}{l}\text { Sendo o espaço de acesso limitado, há dificuldades } \\
\text { de entrada e saída do espaço confinado. }\end{array}$ & $\begin{array}{l}\text { Em uma emergência, a entrada ou saída rápida não é } \\
\text { possível, podendo levar a um acidente ou dificuldade } \\
\text { de resgate. }\end{array}$ \\
\hline Iluminação deficiente & $\begin{array}{l}\text { Baixo grau de iluminação no interior do espaço } \\
\text { confinado. }\end{array}$ & $\begin{array}{l}\text { A baixa luminosidade dificulta tanto as questôes de } \\
\text { acesso assim como a própria execuçáo da atividade. }\end{array}$ \\
\hline Superfície escorregadia & $\begin{array}{c}\text { Devido ao processo de descontaminação com água, } \\
\text { o interior do E.C. se torna escorregadio. }\end{array}$ & $\begin{array}{l}\text { A alta umidade dentro do local aumenta as chances de } \\
\text { ocorrerem quedas, levando assim a lesóes. }\end{array}$ \\
\hline Queda de nível & $\begin{array}{l}\text { Os trabalhadores necessitam acessar pela parte } \\
\text { superior do tanque. }\end{array}$ & $\begin{array}{l}\text { Podem ocorrer quedas, levando a lesôes e } \\
\text { potencialmente morte. }\end{array}$ \\
\hline $\begin{array}{l}\text { Contato com produtos } \\
\text { químicos }\end{array}$ & $\begin{array}{l}\text { Ocorre o uso de substâncias para limpeza interna } \\
\text { dos tanques. }\end{array}$ & $\begin{array}{l}\text { Conforme o produto usado, podem ocorrer irritaçóes } \\
\text { de pele, queimaduras ou dificuldade de respiração. }\end{array}$ \\
\hline Ruídos & $\begin{array}{l}\text { A atividade interna, com o auxílio de equipamentos, } \\
\text { pode causar altos níveis de ruído. }\end{array}$ & $\begin{array}{l}\text { Perda auditiva, stress, fadiga e dificuldade de } \\
\text { comunicação. }\end{array}$ \\
\hline Queda de objetos & $\begin{array}{l}\text { Podem ocorrer a queda de objetos deixado na parte } \\
\text { superior do tanque. }\end{array}$ & Podem ocorrer lesốes devido à queda de objetos. \\
\hline $\begin{array}{l}\text { Atmosfera Imediatamente } \\
\text { Perigosa à Vida ou a Saúde } \\
\text { (IPVS) }\end{array}$ & $\begin{array}{c}\text { Devido aos produtos carregados nos tanques } \\
\text { (principalmente combustíveis), podem ser criadas } \\
\text { atmosferas IPVS. }\end{array}$ & $\begin{array}{l}\text { Efeitos diversos ao trabalhador, através de substâncias } \\
\text { que podem passar despercebidas. Acidentes graves, } \\
\text { irreversíveis ou até mesmo morte. }\end{array}$ \\
\hline
\end{tabular}

Fonte: Próprio autor 


\subsection{ANÁLISE}

Conforme o acompanhamento da execução da descontaminação e manutenção do caminhão tanque pode-se observar os mais diversos problemas, tais como: equipe de trabalho sem treinamento adequado, ausência de vigia/supervisor, falta de medição dos gases durante todo processo de manutenção, ausência de procedimento de emergência e de EPI's. Nota-se que todos esses fatos são facilmente identificados como negligência da empresa ou simples desconhecimento dos riscos envolvidos ou da legislação. Verificam-se dessa forma diversas irregularidades da atividade perante as determinaçôes da NR-33 e NBR-16577:2017 as quais não são cumpridas pela empresa (BRASIL, 2012; ABNT, 2017).

De positivo, deve-se levar em conta que são executados inicialmente a ventilação forçada dos tanques, assim como a descontaminaçáo com água, que juntos reduzem consideravelmente os riscos de uma atmosfera IPVS, apesar de não serem executados as análises de gases, vapores e oxigênio.

Um ponto preocupante é quanto à atividade de solda realizada dentro do tanque, pois devido a uma única pequena abertura de acesso, não ocorre uma boa ventilação, e sendo a fumaça da solda repleta de produtos tóxicos a mesma não se dissipa rapidamente, e acaba respirada pelo operador quando este não possui equipamentos de proteção adequados.

\subsection{SUGESTÃO DE MELHORIAS}

Não é objetivo desse trabalho proferir sugestôes quanto à atividade de descontaminação e manutenção do caminhão tanque, mas sim referentes a segurança e saúde do trabalhador ao exercer sua atividade no Espaço Confinado. A empresa assim deve começar executando uma Análise Preliminar de Risco - APR, de forma a levantar os riscos durante as atividades a serem feitas, sendo que deve ser feita pela equipe da empresa, reunindo responsáveis pela atividade e pessoas qualificadas em segurança. Através da APR tem-se assim os riscos e, dessa forma, pode-se planejar as medidas de controle e eliminação dos mesmos, podendo ser atividades como a medição de gases, ventilação forçada, purga com uso de água no tanque, entre outros.

Quanto à equipe, deve-se verificar se todos possuem os treinamentos, de acordo com a NR 33, conforme a sua partição, seja este vigia, supervisor ou executor da tarefa. A equipe ainda deve possuir equipamentos (EPI's) adequados e em bom uso, os quais são definidos na APR. Sendo neste caso normalmente máscaras, capacetes, luvas, botas e roupa especial (BRASIL, 2012).

Deve-se também treinar e informar os trabalhadores para os procedimentos de emergência e necessidade de resgate, principalmente quando a comunicação de ajuda, tal como a chamada de bombeiros.

A empresa deve também assegurar que o acesso ao Espaço Confinado seja realizado de forma correta, ou seja, somente após a elaboração e emissão da permissão de entrada de trabalho (PET), podendo ser utilizada a sugerida na NR 33 ou de preferência adaptada as especificidades da empresa. Lembrando que é de responsabilidade do supervisor de entrada de preencher e ter capacitação para avaliar se o local está em condiçóes de permitir o acesso e execução do trabalho. A PET só é encerrada após a finalização dos trabalhos executados, o que inclui a remoção de equipamentos e dispositivos e saída de do trabalhador de dentro do tanque, devendo ainda a mesma ser arquivada conforme proposto na NR 33.

Por fim, a atividade de solda quando realizada dentro do espaço confinado é extremamente recomendado o uso de ventilaçáo forçada para remoção dos gases e contaminantes gerados, sendo que tal ventilaçáo deve levar em conta o formato do espaço confinado assim como os acessos de ar (BRASIL, 2012; ABNT, 2017).

Consultando a NBR-16577:2017 verifica-se que a melhor solução para o espaço confinado do caminhão tanque é o uso de um sistema exaustáo forçada com um mangote flexível, de forma a evitar o curto circuito da movimentação do ar, conforme ilustrados nas figuras 4a e 4b.

O uso deste método se justifica devido à circulação de ar, pois sendo a entrada e saída de ar feita por um único local, pode ocorrer o curto circuito conforme mostrado na Figura 4, de forma que não ocorre a renovaçáo do ar no interior do espaço confinado e muito menos a remoção de contaminantes tóxicos ou até mesmo explosivos. Como o mangote é flexível, permite-se o direcionamento da exaustão ao exato ponto de geração dos contaminantes, além de ser um equipamento rápido e fácil de remoção caso seja necessário o resgate do trabalhador.

Conforme já discutido, a preservação da saúde e segurança dos trabalhadores é um fator imprescindível, garantindo assim a força do trabalho adequada além da preservaçáo da vida. Para isso são necessários os cumprimentos das exigências da lei, em especial neste caso da NR 33, a qual determina os processos de segurança em espaços confinados, assim como as responsabilidades dos empregados e empregadores, sejam esses processos administrativos ou práticos. 
Figura 4a - Exaustão em curto circuito

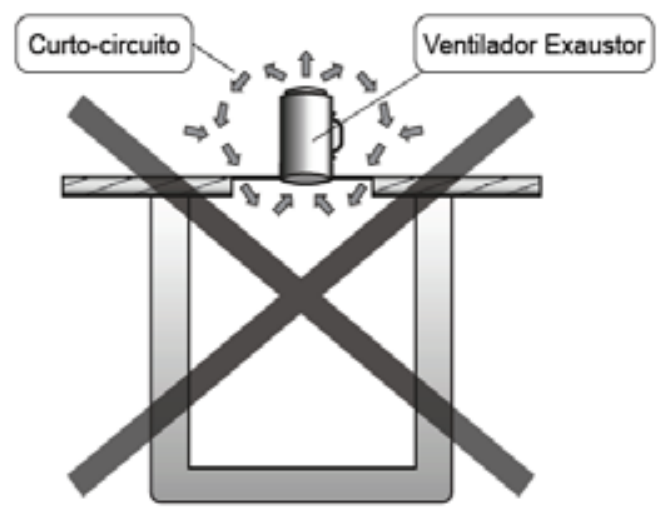

Figura 4b - Exaustão com mangote

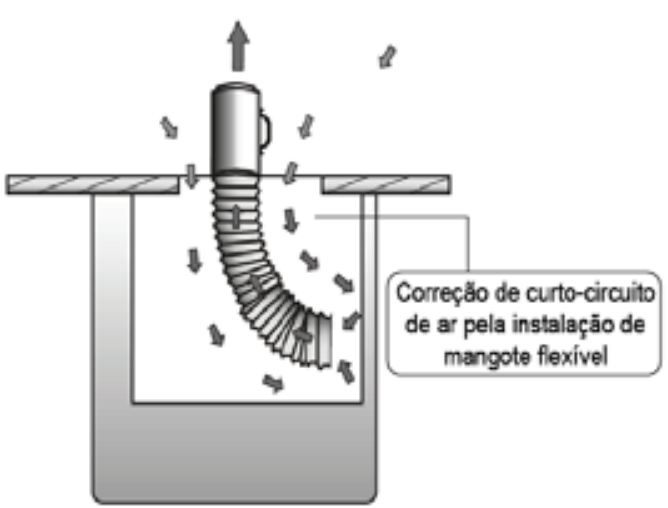

Fonte: NBR 16577:2017.

Dessa forma é essencial que a empresa estabeleça melhores medidas de controle de risco, visando sempre a prioridade de eliminar, neutralizar ou controlar os mesmos. O controle dos riscos se dá assim de diversas formas como uso de equipamentos ou ferramentas, equipamentos de proteçáo individual (EPI), adequados processos de descontaminação e manutenção e treinamento das pessoas envolvidas.

\section{CONSIDERAÇÕES FINAIS}

A realização deste estudo possibilitou a análise, através de visita in loco, da atividade de descontaminação e manutenção do caminhão tanque rodoviário e de que há riscos envolvidos que requerem a implantação de processos de segurança no trabalho em Espaços Confinados, de forma a neutralizá-los ou eliminá-los por completo.

Constatou-se que para a atividade em questão é necessário que os profissionais tenham conhecimentos para prevenção de acidentes, assim como senso de responsabilidade pela própria segurança e de seus pares.

A empresa, a partir deste trabalho, terá subsídios suficientes para atender a NR 33, seguindo as orientaçôes dadas no que tange a implementação da gestão administrativa, através de treinamento dos trabalhadores, uso de APR e PET, assim como nas questóes práticas, como o uso de exaustão durante a atividade de solda no interior do espaço confinado e o controle da atmosfera no local com o uso de medidores de gases.

\section{AGRADECIMENTOS}

Agradecimentos a revisores, colaboradores e agências de fomento.

\section{REFERÊNCIAS}

ASSOCIAÇÃO BRASILEIRA DE NORMAS TÉCNICAS (ABNT). NBR 16577 - Espaço Confinado - Prevençáo de acidentes, procedimentos e medidas de proteçáo. São Paulo. 2017.

BRASIL, Ministério do Trabalho. NR 33 - Segurança e Saúde nos Trabalhos em Espaços Confinados. Portaria n ${ }^{\circ}$ 1409 MTE D.O.U. 31/08/2012.

BRASIL, Ministério do Trabalho. NR 15 - Atividades e Operaçóes Insalubres. Portaria nº 1297 MTE D.O.U. $14 / 08 / 2014$.

CORDEIRO, Glauber José. Gestáo da NR-33 nos serviços de manutençáo e operaçáo da rede de distribuiçáo de gás natural. 2013. 93 f. Trabalho de Conclusão de Curso (Especialização) - Universidade Tecnológica Federal do Paraná, Curitiba, 2013. 
MARTINS, Anderson. Análise do trabalho em espaço confinado: descontaminaçáo e manutenção de vagão tanque ferroviário. 2014. 62 f. Trabalho de Conclusão de Curso (Graduação) - Universidade Tecnológica Federal do Paraná, Curitiba, 2014

NAVARRO, Antônio Fernando. Orientaçóes técnicas para a realizaçáo do trabalho seguro em Espaços Confinados. Rio de Janeiro. 2012. Apresentação disponível em https://www.slideshare.net/antoniofernandonavarro1. Acesso em 17/03/2018.

KLEIN, Litiane. Revista Proteção. Espaço Confinado. O que está faltando? P.40 49, Fev. 2015.

ZAGO, Marcelo. Análise da aplicação da NR-33: segurança e saúde nos trabalhos em espaços confinados em silos de grãos. 2013. 65 f. Trabalho de Conclusão de Curso (Especialização) - Universidade Tecnológica Federal do Paraná, Curitiba, 2013. 